\title{
Intraoperative cholangioscopy with an ultrathin endoscope for hemobilia
}

Hemobilia is a rare but potentially fatal cause of gastrointestinal bleeding [1]. Identifying the source of bleeding may require investigations such as angiography and laparotomy [2].

A 54-year-old man with a history of cholecystectomy was admitted to our hospital with obstructive jaundice and cholangitis. Radiologic imaging showed choledocholithiasis and multiple intrahepatic abscesses. Endoscopic retrograde cholangiopancreatography (ERCP) was unsuccessful due to a bulbar papilla with advanced stenosis of the duodenal bulb, so a percutaneous transhepatic biliary drainage (PTBD) procedure was performed. In the first day after this, massive hemorrhagic drainage was observed. No arterial bleeding was identified by hepatic angiography and a surgical exploration was planned.

At operation, stones and large clots were extracted and active bleeding was identified. Cholangioscopy, using an ultrathin endoscope $(5.9 \mathrm{~mm})$, was performed through the choledochotomy site, and reached the dilated intrahepatic bile ducts. The left biliary system was normal ( Video 1); however, active bleeding was detected from the area of the PTBD catheter in segment 6 ( $\bullet$ Fig. 1; $\bullet$ Video 2 ).

After confirmation of the bleeding by intraoperative Doppler ultrasonography, selective segment 6 portal vein ligation was performed through a high hilar dissection [3] and the bleeding was controlled. Hepaticoduodenostomy and gastrojejunostomy procedures were also performed. No complications occurred and the patient was discharged 6 days after the operation.

\section{Video 1}

Cholangioscopy of the normal left biliary system using an ultrathin endoscope.

\section{Video 2}

Cholangioscopy of the right biliary system using an ultrathin endoscope showing active bleeding.
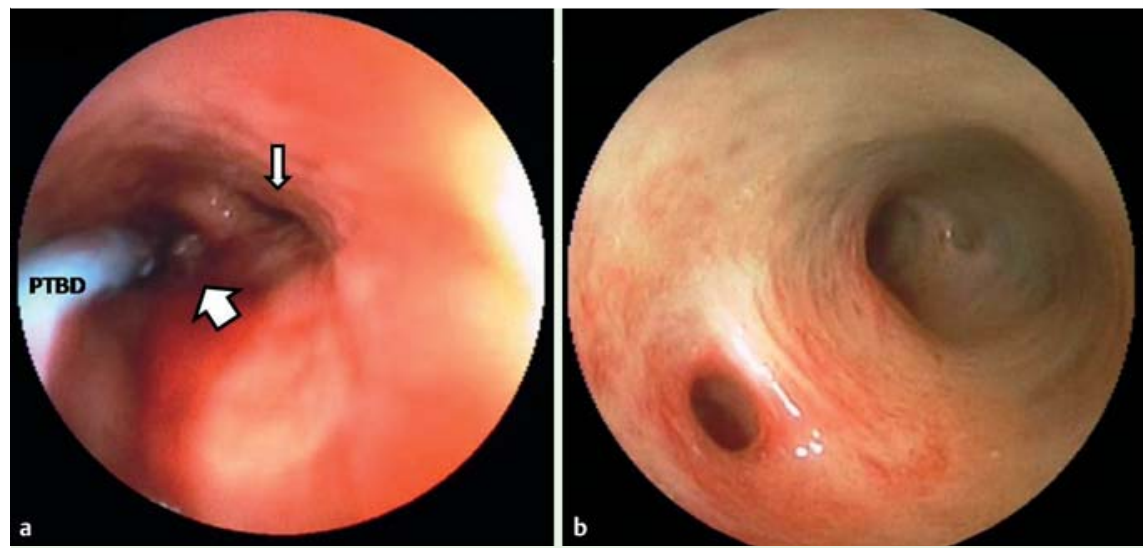

Fig. 1 Cholangioscopic view of the biliary system using an ultrathin endoscope showing: a the segment 7 bile duct (thin arrow) and the hemorrhagic segment 6 bile duct (wide arrow); $\mathbf{b}$ the normal left bile ducts. PTBD, percutaneous transhepatic biliary drainage catheter.

PTBD-associated hemobilia develops in $2-10 \%$ of patients [4]. Although the most suspicious branch of the portal vein is that located in front of the punctured bile duct, this must be verified as the source of bleeding at operation. There are some advantages of using an ultrathin endoscope over a standard rigid cholangioscope, which include superior suction and irrigation ability, and the capability for four-directional maneuverability.

Intraoperative cholangioscopy with an ultrathin endoscope may be useful to detect the source of bleeding in selected patients with hemobilia and can also help the surgeon to plan appropriate surgical management.

\section{Endoscopy_UCTN_Code_TTT_1AR_2AK}

\section{Competing interests: None}

\section{Aydinli' ${ }^{1}$, I. Koruk ${ }^{1}$, S. Koruk ${ }^{2}$,} U. Aydin ${ }^{3}$, A. Kadayifci ${ }^{1}$

1 Department of Gastroenterology, Gaziantep University Medical School, Gaziantep, Turkey

2 Department of Anesthesiology and Reanimation, Gaziantep University Medical School, Gaziantep, Turkey 3 Department of General Surgery and Organ Transplantation, Gaziantep University Medical School, Gaziantep, Turkey

\section{References}

1 Siu WT, Chau CH, Ka Ba Law B et al. Non-operative management of endoscopic iatrogenic haemobilia: case report and review of literature. Acta Gastroenterol Belg 2005; 68 : $428-431$

2 Moodley J, Singh B, Lalloo S et al. Non-operative management of haemobilia. Br J Surg 2001; 88: 1073-1076

3 Aydin U, Yedibela S, Yazici P et al. A new technique of biliary reconstruction after "high hilar resection" of hilar cholangiocarcinoma with tumor extension to secondary and tertiary biliary radicals. Ann Surg Oncol 2008; 15: $1871-1879$

4 Gazzaniga GM, Faggioni A, Bondanza G et al. Percutaneous transhepatic biliary drainage - twelve years' experience. Hepatogastroenterology 1991; 38: 154-159

\section{Bibliography}

DOI $10.1055 / \mathrm{s}-0030-1256897$

Endoscopy 2011; 43: E410

(c) Georg Thieme Verlag KG Stuttgart · New York . ISSN 0013-726X

\section{Corresponding author}

M. Aydinli, MD

Gaziantep Universitesi Tip Fakultesi

Gastroenteroloji BD

27310, Sehitkamil

Gaziantep

Turkey

Fax: +90-342-3603002

maydinli@gantep.edu.tr 